\title{
Mudança organizacional estratégica em um banco público: uma análise a partir da perda da conta movimento
}

\author{
Alexsander Dauzeley da Silva \\ Universidade do Estado de Santa Catarina \\ Graziela Dias Alperstedt \\ Universidade do Estado de Santa Catarina
}

O objetivo do presente artigo foi analisar o processo, o contexto e o conteúdo das mudanças ocorridas no Banco do Brasil no período compreendido entre 1986 e 2012. Para isso foi conduzida uma pesquisa qualitativa a partir de dados primários e secundários, os quais foram analisados por meio da análise de conteúdo semântica e intensiva. Principiando com a perda da conta movimento, são apresentadas as principais mudanças subsequentes na organização. Verificou-se que a mudança no Banco do Brasil foi dada em sua própria razão de existência, ao longo do tempo, em virtude do seu contexto e por meio de um espectro de mudanças menores, mas significativas. A visão comum do mercado sobre as instituições públicas como burocráticas e ineficientes de tempos passados cede lugar à administração das empresas públicas modernas que desejam se transformar em instituições comprometidas com sua função social e, ao mesmo tempo, serem rentáveis e sustentáveis.

Palavras-chave: Banco do Brasil; mudança; estratégia; contexto.

El cambio estratégico organizacional en un banco público: un análisis de la pérdida del cuenta movimiento

El objetivo de este trabajo es analizar el proceso, el contexto y el contenido de los cambios en el Banco de Brasil en el período comprendido entre 1986 y 2012. Para ello se realizó un estudio cualitativo de los datos primarios y secundarios, los cuales fueron analizados utilizando el análisis de contenido semántica y intensiva. A partir de la pérdida de la cuenta de efectivo, se presentan los principales cambios posteriores en la organización. Se encontró que cambiar el Banco de Brasil se dio sobre su razón de la propia existencia, a través del tiempo, en virtud de su conexión y mediante una serie de cambios menores, pero significativos. El punto de vista común de mercados en las instituciones públicas como los tiempos pasados burocrático e ineficiente da paso a la administración de las empresas públicas que deseen convertirse en moderno en las instituciones comprometidas con la función social y al mismo tiempo ser rentable y sostenible.

Palabras clave: Banco de Brasil; cambio; estrategia; contexto.

Artigo recebido em 14 fev. 2012 e aceito em 19 fev. 2013. 
Strategic organizational change in a public bank: an analysis from the loss of the cash account The aim of this paper is to analyze the process, context and content of strategic change in the Bank of Brazil in the period comprehended between 1986 and 2012. For this, was conducted a qualitative study from primary and secondary data, which were analyzed using semantic and intensive content analysis. Beginning with the loss of the cash account, are presented the main subsequent changes in the organization. It was found that changing the Bank of Brazil was given on its own existence ratio over time by virtue of its connection and through a range of minor but significant changes. Although the vision of the market on public institutions are still tied to the inefficient bureaucratic organizations results gives way to modern administrations of public companies who wish to transform their institutions into companies committed to its social role and at the same time, prove profitability and sustainability.

KEYWORDs: Bank of Brazil; change; strategy; context.

\section{Introdução}

O Banco do Brasil sempre desempenhou um papel de grande relevância no cenário nacional, tendo como maior acionista o próprio governo federal e para o qual serviu de agente financeiro até 1986, quando perdeu o direito à conta movimento, que promovia o suprimento automático de recursos financeiros ao banco.

A interrupção da conta movimento deflagrou um processo de mudança radical no Banco do Brasil, o qual precisou concorrer com os bancos privados na captação de recursos no mercado, experiência essa que o banco não possuía. Este episódio marca o início de uma grande mudança no Banco, que passou a caracterizar-se como um conglomerado financeiro (César, 2010).

Diante deste evento, o Banco do Brasil teve de se adaptar às profundas alterações ocorridas no sistema financeiro brasileiro, capitaneadas pelas mudanças tecnológicas, que oportunizaram novos modelos de atuação para os bancos.

Da especialização por segmentos à concentração no setor bancário, com elevado número de fusões e aquisições, o sistema financeiro nacional sofreu inúmeras mudanças somadas às questões sociopolíticas, regulacionais, econômicas, mercadológicas e tecnológicas.

Todas essas transformações resultaram na modernização do sistema financeiro e na melhor qualidade dos serviços prestados, o que exigia do Banco do Brasil uma reestruturação para se tornar mais competitivo. Em 1994, o Plano Real agravou a situação dos bancos, pois a estabilização monetária trouxe consigo a dificuldade de obter ganhos pela aplicação de recursos no mercado financeiro (César, 2010).

Diante de toda essa gama de transformações questiona-se: como o Banco do Brasil se ajustou a esse novo cenário? O que mudou no Banco? Como os seus dirigentes interpretaram o contexto das mudanças? São essas perguntas que este trabalho se propõe a responder.

Tendo em vista esses questionamentos e utilizando-se como base a abordagem contextualista de Pettigrew (1988), objetivou-se com esse trabalho analisar o processo, o contexto e 
o conteúdo das mudanças ocorridas no Banco do Brasil no período compreendido entre 1996 e 2012. Este esforço parte da compreensão de que entender onde, como e por que as organizações públicas mudam parece ser uma questão central e desafiadora para os acadêmicos da administração pública e de diversas outras disciplinas.

A literatura na área de administração tem concentrado poucos esforços nos últimos anos no que se refere ao estudo da mudança estratégica em instituições bancárias públicas. Uma revisão sistemática da literatura nacional e internacional dos últimos quatro anos identificou muitos trabalhos em instituições bancárias (César, 2010; Ali e Baloch, 2010; Anjani e Dhanapal, 2012), porém grande parte desses trabalhos concentra-se na área de gestão de pessoas e/ou em instituições privadas. Há também muitos trabalhos acadêmicos tendo como objeto de análise o Banco do Brasil, mas nenhum com o objetivo aqui proposto.

Observa-se que estudos de caso mais recentes sobre mudanças estratégicas em instituições financeiras públicas brasileiras não têm sido publicados nos principais periódicos nacionais ou internacionais, pelo menos com o recorte que aqui se pretendeu dar. Isto sugere que, longe de ser um assunto esgotado, existe uma carência por mais estudos empíricos no setor bancário, especialmente o público e brasileiro, tendo em vista as grandes mudanças ocorridas nos últimos anos neste setor no país. Dados obtidos com este estudo de caso podem contribuir de forma importante para uma ampliação da compreensão da mudança organizacional, principalmente sob os cenários mais atuais, numa visão contextualista.

O presente artigo apresenta, em um primeiro momento, a mudança estratégica como fundamento teórico. Logo após, se volta para a abordagem contextualista liderada por Pettigrew e utilizada como base metodológica para este estudo. Na sequência são apresentados os procedimentos metodológicos, os dados e sua análise, além das considerações finais.

\section{Mudança organizacional estratégica e a proposta de Pettigrew}

A literatura, de uma forma geral, defende que a mudança estratégica está relacionada ao ambiente externo, como alterações regulatórias, revoluções tecnológicas, dentre outros, bem como aos fatores organizacionais internos como ações gerenciais, recursos e capacidades (Vicente-Lorente e Zúñiga-Vicente, 2006).

Pettigrew (1996) admite que a mudança organizacional envolva alterações intelectual, cognitiva, estrutural e material, e a visualiza como um processo humano complexo em que cada um desempenha sua parte. Buscando uma visão contextualista para o estudo da mudança estratégica, o autor propõe a análise de três aspectos essenciais: o contexto, o processo e o conteúdo da mudança.

De acordo com Pettigrew (1985b), o conteúdo da mudança organizacional refere-se à área, no estudo, onde a transformação propriamente dita está ocorrendo e pode ser classificado de acordo com uma seleção mais abstrata, que definiria a mudança como radical, incremental, tecnológica ou centrada em mudanças nos papéis. A formulação do "conteúdo" suporia, assim, o controle do contexto e do processo, e o conteúdo poderia ser compreendido 
como as áreas específicas de mudança que estão sob análise, tais como a estrutura, a tecnologia e assim por diante.

O "processo" de mudança diz respeito às ações, reações e interações das partes (Pettigrew, 1996). Sob este enfoque, o estudo da mudança considera os aspectos humanos e sociais, tais como os padrões de interação, a influência das crenças, dos valores, dos esquemas interpretativos e das percepções humanas. Child e Smith (1987) contribuem para essa discussão ao perceberem que, apesar do ambiente objetivo influir na efetividade organizacional e na escolha da estratégia apropriada, é o ambiente percebido que melhor se relaciona com a tomada de decisão. A "arena cognitiva" pressupõe que o contexto passa a ser compreendido como uma construção mental, cuja existência está atrelada à elaboração por parte dos membros da organização motivados pelas suas crenças, ideologias e experiências de vida. Van de Ven (1992) define o processo de quatro maneiras. A maneira como ele é interpretado pode reduzir as chances de sucesso ou de entendimento global do fenômeno da mudança estratégica. Nesse trabalho, o processo de mudança é compreendido de forma teleológica.

Com relação ao "contexto", Pettigrew (1996) o divide em interno e externo. O contexto externo compreende os ambientes social, econômico, político e competitivo que envolvem a organização. Por outro lado, o contexto interno refere-se à estrutura, à cultura organizacional e ao contexto político da organização. É na análise do contexto que a teoria institucional merece destaque.

A teoria institucional, em linhas gerais, é uma alternativa à concepção racional que predomina nos estudos organizacionais e supõe que toda decisão pode ser dirigida por critérios racionais de escolha. Essa visão, ainda predominante no estudo das organizações, significa a superação do irracional pela ciência positiva, a qual compreende as organizações como instrumentos técnicos, racionalmente planejados para fins determinados. A ideia de organização também se alterou, dando origem à concepção de organização como fenômeno socialmente construído, resultado não só das ações humanas intencionais e planejadas, como também de suas interações culturais e políticas e de processos cognitivos e simbólicos, ou seja, de um conjunto de processos sociais não racionais, pelo menos no sentido econômico (Crubellate, Grave e Mendes, 2004). Nesse sentido, a perspectiva institucional destaca a presença de elementos culturais - valores, símbolos, mitos, crenças e os sistemas de profissionalização (Carvalho, Vieira e Lopes, 1999).

A visão institucional afirma que as organizações têm duas dimensões essenciais: a técnica e a institucional. Assim, o ambiente técnico caracteriza-se pela troca de bens e serviços, enquanto o ambiente institucional conduz ao estabelecimento e à difusão de normas de atuação, necessárias ao alcance da legitimidade organizacional. Acrescenta-se que é fundamental o entendimento de que a natureza da atividade de cada organização determina a maior ou a menor importância de cada uma dessas dimensões (técnica ou institucional) na formulação das estratégias de ação (Machado-da-Silva, Fonseca e Fernandes, 1999).

A literatura sobre a perspectiva institucional faz uso do conceito de isomorfismo a fim de esclarecer a forma como as características da organização são modificadas para que ocorra o ajuste com as características do ambiente. O isomorfismo força uma organização a procurar 
assemelhar-se a outras que enfrentem o mesmo conjunto de condições do ambiente, ou seja, elas se modificam na direção da compatibilidade com as características ambientais (Dimaggio e Powell, 2005).

O fato de haverem mecanismos indutores de isomorfismo é um dos pontos centrais da teoria institucional. São eles os determinantes socioeconômicos que levam as organizações a adotarem formas e práticas organizacionais semelhantes (Vasconcelos, 2004).

Nesse sentido, Dimaggio e Powell (2005) buscam explicar o motivo pelo qual as organizações tendem a ser tão similares e identificaram três mecanismos de mudanças isomórficas institucionais: a) Isomorfismo coercitivo - deriva de influências políticas e do problema da legitimidade; b) Isomorfismo mimético — resulta das respostas padronizadas à incerteza; e c) Isomorfismo normativo - associado à profissionalização.

As regulamentações do governo e as expectativas culturais com poder de impor uniformidade para as organizações constituem as forças coercitivas do ambiente. Para Dimaggio e Powell (2005), o isomorfismo coercitivo trata da pressão, formal ou informal, feita sobre a organização e relacionada à influência política ou a problemas de legitimação (Gimenez, Hayashi e Grave, 2007).

O segundo tipo de isomorfismo identificado por Dimaggio e Powell (2005) está relacionado com os processos miméticos. Em resposta à incerteza do ambiente, muitas organizações adotam outra como modelo de imitação. Uma das vantagens do comportamento mimético é a possibilidade da solução viável e com poucos gastos para um problema com causas ambíguas.

A pressão normativa é a terceira fonte de mudança organizacional (Dimaggio e Powell, 2005) e deriva, principalmente, da profissionalização. Gimenez, Hayashi e Grave (2007) afirmam que a pressão normativa está relacionada à profissionalização, ou ao seu grau, e afeta o isomorfismo principalmente de duas maneiras: (i) pela construção e consolidação de uma base cognitiva e legitimação para a ocupação; e (ii) pela formação e manutenção de networks profissionais.

De uma forma geral, tão importante para o sucesso da análise contextualista quanto da descoberta dos seus componentes é o estabelecimento de relações entre o contexto, o processo e o conteúdo. O reconhecimento de que os processos de mudança são incorporados em contextos e só podem ser estudados como tal cria a necessidade de conceber e investigar esse campo interativo em que as alterações emergem ao longo do tempo (Pettigrew, 2001).

\section{Procedimentos metodológicos}

Para atender aos objetivos do presente estudo, foi realizada uma pesquisa qualitativa na forma de um estudo de caso único e tradicional e a partir de um processo circular de pesquisa (Flick, 2009). O Banco do Brasil apresenta dimensões, história e relevância justificáveis na condução de uma pesquisa que resulte em um estudo de caso único e representativo (Yin, 2007).

Para o levantamento dos dados que subsidiaram a pesquisa foram realizadas entrevistas focalizadas (Flick, 2009) de aproximadamente uma hora cada, com pessoas-chave pertencen- 
tes à organização. As entrevistas, em número de 10, foram gravadas e transcritas e retomadas diversas vezes a fim de confrontá-las com as informações obtidas por meio dos dados secundários e da revisão sistemática da literatura.

Os entrevistados são administradores que ocupam cargos de gestão tática ou estratégica há mais de 10 anos e são funcionários do Banco do Brasil há mais de 20 anos. Buscou-se selecionar pessoas com considerável experiência na instituição, que vivenciaram, de alguma forma, os principais processos de mudança. Os cargos que ocupam ou ocuparam são bastante diversificados, o que serviu para ampliar a abrangência das visões que subsidiaram a construção da pesquisa. A identidade, cargo e lotação dos entrevistados foram propositalmente omitidos, como forma de proteger os entrevistados e dar aos mesmos maior grau de liberdade no relato dos fatos e na expressão de suas ideias.

Além das entrevistas, a análise documental foi muito relevante, pois o acesso a atas e documentos que revelam a memória passada serviu para atenuar o número reduzido de entrevistas realizadas, considerando o tamanho da organização. Os pontos convergentes entre as entrevistas e os documentos foram ressaltados como eventos primários ou mais significativos, seguidos dos pontos com menor ocorrência, que também foram considerados. As informações prestadas pelos entrevistados foram comparadas com a documentação que as descrevia, garantindo a fidedignidade dos dados (Bauer e Gaskell, 2012) no momento da codificação.

Foi necessária a realização de uma série de ajustes nas informações, uma vez que as datas e a sequência dos acontecimentos muitas vezes não eram compatíveis. Assim, a pesquisa documental ocorreu sobre um considerável acervo bibliográfico a respeito do Banco do Brasil.

Para a análise dos dados foi utilizada a Análise de Conteúdo (AC) semântica (Navarro e Díaz, 1994), na qual se busca o significado das expressões textuais. Das estratégias de AC disponíveis na literatura, escolheu-se a intensiva, pois nela integram-se todos os elementos presentes no texto, os quais têm suas relações construídas sistematicamente, integrando e relacionando os elementos contidos nos dados que pudessem proporcionar uma análise do contexto, do processo e do conteúdo das mudanças estratégicas no Banco do Brasil.

A estratégia intensiva utilizada foi a intertextual (Navarro e Díaz, 1994) para facilitar o sentido do texto por meio de suas relações com outros textos. E, ainda, a partir do método discriminativo, o qual converte cada texto em domínios analíticos diferentes, com vistas a realizar comparações entre eles.

A fase de análise propriamente dita começou estabelecendo as unidades básicas de relevância (significação) extraídas do texto. Estas unidades, denominadas unidades de registro (Navarro e Díaz, 1994), foram aquelas informações sobre o processo, o contexto e o conteúdo das mudanças na instituição extraídas a partir do confronto das informações encontradas na literatura, mais especificamente com o modelo de Pettigrew. Para evitar a mera identificação genérica das "unidades de registro" (Navarro e Díaz, 1994), foi necessário não apenas detectá-las, mas também localizá-las, através das unidades de contexto que são unidades de registro de ordem superior, e que definem o sentido que se busca. Neste caso, o critério utilizado foi o textual (Navarro e Díaz, 1994). Uma vez determinados os tipos de unidades de registro e de contexto, os dados foram codificados, ou seja, todas as unidades de registro encontradas 
foram vinculadas às suas respectivas unidades de contexto. Assim, as unidades de registro puderam ser contabilizadas e relacionadas (Navarro e Díaz, 1994).

O passo seguinte foi a categorização propriamente dita. A categorização consistiu em efetuar a classificação das unidades de registro previamente codificadas e interpretadas em suas correspondentes unidades de contexto, segundo as semelhanças e diferenças que nelas fosse possível observar, de acordo com um critério de classificação. Nesse trabalho, o critério utilizado foi o semântico (Bauer e Gaskell, 2012). A principal categoria desta pesquisa é a mudança organizacional estratégica e as subcategorias são o processo, o contexto e o conteúdo das mudanças. Assim, para cada subcategoria foram definidas as propriedades que as representam, identificadas no material coletado, interpretadas e relacionadas com a literatura.

\section{Apresentação e análise dos dados}

\subsection{O Banco do Brasil}

Fundado em 1808 pela família imperial, o Banco do Brasil possui o primeiro número de CNPJ do país, completando 204 anos ao tempo deste estudo. É um dos braços do Sistema Financeiro Nacional (Bueno, 2008), exercendo papel de distribuidor de numerário, financiador da agricultura, captador de divisas e fomentador da atividade industrial (Banco do Brasil, 2008b).

O Banco do Brasil é constituído de uma sociedade anônima aberta, de economia mista, organizada sob a forma de um banco múltiplo, com sede em Brasília, e sua duração é por prazo indeterminado. Rege-se por meio de um estatuto e pelas disposições legais que lhe sejam aplicáveis (Banco do Brasil, 2009c, 2008b, 2007b).

A empresa tem por objeto a prática de todas as operações bancárias ativas, passivas e acessórias, a prestação de serviços bancários, de intermediação e suprimento financeiro sob suas múltiplas formas e o exercício de quaisquer atividades facultadas às instituições integrantes do Sistema Financeiro Nacional (Banco do Brasil, 2009d).

O Banco do Brasil é também um dos maiores bancos de varejo do país, sendo líder em vários segmentos. O tamanho de sua estrutura salienta a importância que tem para o sistema financeiro nacional. A organização possui mais de 80 mil funcionários em agências no Brasil e no exterior, e mais de 20 milhões de clientes (Banco do Brasil, 2007a).

Em seu Relatório de Análise de Desempenho, o Banco do Brasil apontou, no balanço patrimonial do exercício encerrado em 31/12/2011, mais de R\$ 981,2 bilhões no total de ativos/passivos, $\mathrm{R}$ \$ 58,4 bilhões de patrimônio líquido e $\mathrm{R}$ \$ 12,1 bilhões de lucro líquido (Banco do Brasil, 2012).

A organização possui, atualmente, mais de 36 milhões de contas-correntes, 15 mil pontos de atendimento em mais de 3 mil cidades e em 42 países e mais de 56 milhões de clientes (deve-se ressaltar que, neste número, são considerados os poupadores e clientes das subsidiárias). São mais de 5.200 agências e 43 mil terminais de autoatendimento, além de 113 mil funcionários (Banco do Brasil, 2012). 
O Banco do Brasil foi criado no dia 12 de outubro de 1808, por meio de um decreto do príncipe regente d. João, como braço financeiro da corte portuguesa no Brasil. Desde então, a organização presenciou a declaração da independência do país, foi liquidada no ano de 1833, retomou suas atividades e sofreu um processo de fusão com o Banco do Rio de Janeiro. Passou por diversas alterações em suas funções e em sua razão social. Vivenciou a monarquia, o império, a república, os governos civis e militares e dezenas de crises financeiras nacionais e globais (Franco e Pacheco, 1979; Bueno, 2008; Banco do Brasil, 2008b).

Na Itália, por meio de seus escritórios em Roma, Nápoles e Pistoia, o Banco do Brasil auxiliou no pagamento de soldos aos "pracinhas", durante a Segunda Guerra Mundial. Abriu agências no Paraguai (1941) e, até o ano de 1971, mais 13 dependências no exterior, entre elas Nova Iorque (1969) (Lima, 2008).

A história do Banco do Brasil é entrelaçada com a do próprio país, e sua participação nos eventos políticos foi de caráter determinante na implantação de um sem-número de políticas financeiras, comerciais, exteriores e regulatórias (Franco e Pacheco, 1979; Banco do Brasil, 2008a).

Com tão vasta história, perpassando cenários de tamanha heterogeneidade, a instituição faz-se um campo de estudos para a mudança organizacional. As alterações profundas a que o corpo organizacional foi submetido permitiram a sobrevivência da instituição financeira, que foi o primeiro banco do país (Franco e Pacheco, 1979; Lima, 2008).

Dentro dessa perspectiva, buscou-se, com a pesquisa, analisar as mudanças estratégicas no Banco do Brasil, destacando seu contexto, processo e conteúdo, a partir da perda da conta movimento. Tais mudanças passam a ser descritas a seguir.

\subsection{As mudanças no Banco do Brasil}

As mudanças no Banco do Brasil, desde o início da pesquisa, pareceram ser uma constante inevitável, ao menos sob as condições aqui descritas. A própria economia brasileira mostrouse dinâmica e fornece um contexto de influência para a transformação das organizações nela inseridas ou dela intervenientes (Bueno, 2008; Serra, 1982).

O Banco do Brasil atravessou grandes processos de mudança em sua história e, de forma muito expressiva, nos últimos 25 anos. Estas mudanças foram orientadas, sobretudo, pelos modelos norte-americanos de gestão (Rodrigues, 2004).

Como constataram Child e Smith (1987), a mudança passa por diferentes fases, para as quais não existe um fim ou início claramente delimitados. Assim, determinados eventos podem ser os principais motivadores da mudança estratégica e organizacional, ainda que não se acredite que um acontecimento tenha sido isoladamente o único responsável pelo início do processo de mudança.

No caso do Banco do Brasil, a perda da conta movimento (que caracteriza a função de banco do governo, mediante o controle das operações de comércio exterior, o recebimento dos depósitos compulsórios e voluntários dos bancos comerciais e a execução de operações 
de câmbio em nome de empresas públicas e do Tesouro Nacional, de acordo com as normas estabelecidas pela Superintendência da Moeda e do Crédito - Sumoc - e pelo Banco de Crédito Agrícola, Comercial e Industrial) pareceu constituir-se, de acordo com os diversos dados levantados, o principal divisor de águas entre a antiga organização e o vultuoso banco público, voltado ao mercado conforme se pode observar.

Contudo, outros eventos, como o fim do Plano Real, a crise de liquidez e o acirramento da concorrência, foram determinantes para que o processo de mudança fosse iniciado e conduzido.

De igual forma, foram observados períodos em que as mudanças continuaram ocorrendo, não apenas como resposta aos eventos precedentes, mas, também, em reação aos contextos interno e externo.

\subsection{0 contexto da mudança no Banco do Brasil}

\subsubsection{O contexto externo}

O cenário político, econômico-financeiro, competitivo e social no qual o Banco do Brasil estava inserido no início do período considerado na pesquisa foi o grande motivador da mudança estratégica na organização.

Em todas as entrevistas realizadas, a perda da conta movimento emergiu como o grande divisor de águas entre o antigo Banco do Brasil, sólido, valoroso e confiável, mas, sobretudo afastado do mercado, e a nova organização atual, fortemente orientada à competição e à obtenção de resultados, ainda que sem o intento de preterir seus objetivos sociais.

As mudanças até a perda da conta movimento, de acordo com os entrevistados, se davam de forma mais discreta e restrita do que nos anos subsequentes. A partir deste evento, no entanto, ficou bastante aparente que as mudanças passaram a acontecer em maior escala no seu contexto interno e o próprio conteúdo das mudanças pareceu se tornar mais significativo.

Ficou claro que a perda da conta movimento não foi a única situação, ou evento em si, que transformou a organização. A própria retirada, por parte do governo federal, da atribuição do Banco do Brasil de ser o caixa do país foi reflexo de pressões externas e de uma nova visão política, econômica e social que se instaurava na nação àquela época.

A perda da conta movimento em 1986 e a consequente realocação do Banco do Brasil no cenário financeiro nacional desestabilizou os alicerces da instituição. Os símbolos, valores e, por fim, a cultura da organização foram profundamente alterados com a nova realidade. Essa alteração gerou uma série de tensões no contexto interno, pressionando por mudanças nos fundamentos organizacionais.

Como resultado da inadequação dos antigos valores organizacionais em face do novo contexto, houve uma série de mudanças internas menores que, somadas, trouxeram uma completa reorientação na instituição. Mudanças menores - mas nem sempre menos impor- 
tantes - se mostravam, ao cabo de anos, tão promotoras da mudança quanto eventos mais expressivos.

Entre as grandes alterações no contexto da instituição, destaca-se a que se deu em 1994, quando o Plano Real foi implantado no Brasil. A cessão dos rendimentos derivados das operações em ambiente altamente inflacionário, como resultado direto e desejado do plano, foi um grande impulsionador da mudança no Banco do Brasil.

Algumas mudanças que anteriormente não obtiveram sucesso na instituição foram trazidas novamente para sua concretização, com a nova situação econômica. É sabido que algumas importantes instituições financeiras não conseguiram se adaptar eficazmente a esta nova conjuntura e, por fim, sucumbiram.

Muitas das mudanças que estavam sendo implementadas em uma marcha relativamente lenta tiveram de ser apressadas a fim de tornar o Banco do Brasil competitivo. De outra forma, caso a adaptação ao novo ambiente não lograsse efeito, a organização poderia ter seguido o funesto destino de outras empresas, justamente por não ser capaz de conviver com a mudança no seu contexto (Pettigrew, 1985b; 2001; Child e Smith, 1987).

Em outra situação, o contexto externo foi preponderante para catalisar o processo de mudança da organização. Com o surgimento da crise econômica internacional de 2008, disparada pela quebra dos mercados imobiliários subprime estadunidenses, a instituição passou a desenvolver um papel-chave no cenário econômico brasileiro.

Conforme relatado por funcionários de um órgão administrativo da empresa, àquela época, o governo federal, atento à ameaça de contaminação da confiança na economia nacional pela histeria que se iniciara nos Estados Unidos e se alastrava rapidamente pela Europa, ensejou aumentar a oferta de crédito com vistas ao estímulo ao consumo.

De acordo com os relatos, os bancos privados seguiam a tendência internacional retraindo a oferta de crédito e elevando as taxas de juros, temendo o aumento da inadimplência e a exposição de seu patrimônio, a exemplo do que ocorrera mesmo com grandes e tradicionais instituições pelo globo.

Neste momento, o Banco do Brasil sofre uma intervenção direta do governo federal, que nomeia um novo presidente para assumir a missão de, na contramão do mercado, ofertar crédito em abundância para empresas, governo e pessoas físicas. Alguns meses mais tarde, assim que o mercado verificou que as exposições do Banco do Brasil e da Caixa Econômica Federal resultaram em grande expansão da base de crédito, os bancos privados, num movimento mimético, passaram também a ofertar crédito e em condições mais vantajosas. O contexto determinou uma mudança profunda não só na estratégia da empresa, como também em sua estrutura e políticas.

O contexto externo da instituição foi também avaliado na figura do setor (Child e Smith, 1987) ou da concorrência que, por sua vez, foi importante impulsionador da mudança no Banco do Brasil após a perda da conta movimento. A atuação agressiva dos competidores no mercado bancário teve papel de criar pressões sobre todos os níveis e todas as esferas organizacionais, desde o portfólio de produtos, práticas gerenciais, despesas administrativas, índices de eficiência até o atendimento ao cliente. 
O Banco do Brasil, como instrumento de gestão econômico-financeiro nacional, sofreu, em grande medida, os reflexos das decisões políticas das heterogêneas coligações partidárias que estiveram no governo federal nos últimos anos (Rodrigues, 2004). É bastante importante observar os interesses governamentais como estimuladores da mudança, sobretudo se considerado o conceito de Hardy (1996) sobre poder como uma força que afeta saídas.

O contexto externo promovido pela legislação brasileira a respeito das instituições públicas também se mostrou muito interferente na estratégia organizacional. O Banco do Brasil, como as demais empresas públicas, sempre foi bastante cerceado pelas rígidas regras que lhe exigem altos níveis de accountability. Ademais, completas impossibilidades, como no caso da incorporação de tecnologia pelas vias da concorrência, acabaram por criar estratégias inovadoras para a organização. Pode-se afirmar, portanto, que este aspecto do contexto institucional, representado pelas forças coercitivas do ambiente (Dimaggio e Powell, 2005), também foi um importante promotor de mudança no conglomerado.

Mas as políticas governamentais também criaram oportunidades ao fornecer acesso relativamente exclusivo a algumas áreas do mercado, bem como, ulteriormente, permitiram a quase equiparação da estratégia empresarial com a concorrência, no tocante à incorporação de empresas menores.

A incorporação do Banco do Estado de Santa Catarina (Besc) em 2008, por exemplo, foi possível através de situações específicas e inéditas no país. Posteriormente à incorporação, a Medida Provisória (MP) 443 aumentou a liberdade de o Banco do Brasil adquirir instituições financeiras. Com esta medida, a organização passaria a possuir as mesmas prerrogativas das instituições privadas (Lima, 2008).

Com a experiência advinda da incorporação do Besc, o Banco do Brasil pôde adquirir importante conhecimento e concretizar a aquisição do Banco Nossa Caixa, de São Paulo, em 2009. Neste tipo de ação, pode-se perceber claramente a influência do setor (Child e Smith, 1987) como motivador para a mudança.

Historicamente, o Banco do Brasil fora, relativamente, menos presente na capital do estado de São Paulo do que nos demais estados da federação. A estratégia de aquisição do Banco Nossa Caixa objetivou um avanço considerável em um mercado extremamente disputado e de difícil penetração. Motivação semelhante levou o Banco do Brasil a realizar uma audaciosa compra de ações do Banco Votorantim em janeiro de 2009, não assumindo o controle da organização, mas se tornando o segundo grande acionista desta empresa com considerável experiência no ramo de financiamento de veículos. Esta última estratégia resultou em alguns prejuízos em virtude do desaquecimento do mercado de veículos seminovos e do aumento da inadimplência, em função da conjuntura nacional.

No início de 2012, o Banco do Brasil concluiu a compra do EuroBank, nos Estados Unidos, adicionando-o ao rol de instituições adquiridas que incluía o Banco da Patagônia, na Argentina, comprado em 2010. O primeiro caracterizou-se por uma aquisição pequena com o intuito de acompanhar a expansão dos negócios de empresas e pessoas físicas do Brasil no exterior. Todavia, funcionários da Empresa creem que se trata de aquisição de expertise para passos mais pródigos em um futuro próximo. Um pouco mais prática seria a aquisição do Ban- 
co da Patagônia, que poderia trazer negócios com relativa importância para a instituição. O que parece ser consenso entre os entrevistados é que o Banco do Brasil busca uma expansão de seus negócios no exterior como forma de acompanhar movimentos semelhantes da concorrência, ampliando suas oportunidades e opções de captação e aplicação, caracterizando um comportamento mimético (Dimaggio e Powell, 2005).

O Banco do Brasil ainda adquiriu no final de 2011 o direito de explorar as agências de correios como correspondentes bancários (Banco do Brasil, 2012) a um considerável custo, o que lhe valeu uma estratégia de mão dupla: reduziu a participação de um dos seus principais concorrentes privados nos segmentos de baixa renda e na capilaridade de sua rede de distribuição, e ainda angariou uma estrutura física, logística e humana cada vez mais valiosa no atendimento aos clientes com menor potencial de negócios, mas cuja bancarização é alvo estratégico das políticas de inclusão do governo federal.

Ainda entre 2011 e 2012, outra importante mudança no Banco do Brasil foi a reorientação da empresa para o atendimento ao cliente. A instituição investiu pesadamente em um modelo de Customer Relationship Management (CRM) que, muito além do que a simples alteração de sistemas de informação corporativa, tratou-se de uma nova abordagem da organização em relação a seus clientes. A migração da visão foi relativamente súbita e um tanto conturbada, uma vez que surgiram problemas, sobretudo dos sistemas de informação que não estiveram tempestivamente disponíveis. A base funcional pareceu absorver bem o novo ferramental, embora seja difícil avaliar o grau de internalização do novo paradigma que, certamente, demanda mais tempo do que a simples aclimatação com novos sistemas de computação.

Já em 2012, com a cronicidade da crise financeira internacional, o governo federal adotou a estratégia de redução dos juros bancários para estimular o acesso ao crédito por parte de empresas, governo e pessoas físicas. O modus operandi consistiu em acionar os bancos públicos como líderes deste processo, forçando a concorrência a segui-los sob pena de migração massiva de seus ativos aplicados. O mesmo ocorreu, ainda no mesmo ano, com o preço das tarifas bancárias, pois, com a redução incentivada do spread, os bancos, de maneira geral, apresentaram a tendência de aumentar a tarifação sobre seus serviços e produtos. Mais uma vez, os bancos públicos foram instrumentos para liderar o processo.

Todavia, o mercado de capitais costuma não ver com bons olhos tais pressões governamentais na gestão da instituição, pois significativa parte das ações desta empresa de economia mista está na Bolsa de Valores. Estas influências sobre a administração do banco muitas vezes são interpretadas como execução de políticas econômicas e sociais que visam o bem público, mesmo que à custa da remuneração do acionista — o que nem sempre se concretiza —, mas que, no final do processo, acabam por reduzir o preço de mercado dos papéis em circulação.

Estes fatos ilustram o papel do contexto externo nas políticas da organização, em um entrelaçamento da função do governo e do assédio da concorrência (Child e Smith, 1987). Não existe, de acordo com o levantado nesta pesquisa, como dissociar a mudança no Banco do Brasil do seu contexto externo. 


\subsubsection{O contexto interno}

Diversas foram as pressões internas para a mudança na organização. Grupos políticos na Empresa se formaram para defender suas posições e o acesso aos recursos organizacionais, quer sob a forma de cargos e salários, quer sob a manutenção do poder ou acesso a informações, conforme já observara Pettigrew (1985b) em seu estudo de caso.

Haja vista a extensão intercontinental da empresa, é muito difícil a análise abrangente do contexto interno organizacional à época das principais mudanças. De outra forma, foi possível detectar na coleta de dados informações que podem revelar os principais aspectos do contexto interno.

Assim, no contexto interno, os mitos, metáforas e símbolos (Pettigrew, 1985b) se mostraram muito presentes nos funcionários do Banco do Brasil, de diversas formas. O orgulho de uma história que se confunde com a da própria nação à época de sua independência e a necessidade de manter uma grande companhia nas mãos do povo foram exemplos de símbolos e valores que tiveram importante influência nas mudanças organizacionais. Estes mitos e a própria cultura auxiliaram na criação de vantagem competitiva para a organização (Hardy, 1996), revelando a ideia de uma organização formada não somente por ações racionais e planejadas, mas sobretudo por interações culturais e políticas e de processos cognitivos e simbólicos (Carvalho, Vieira e Lopes, 1999).

Os entrevistados foram praticamente unânimes ao revelar o forte simbolismo entrelaçado no corpo funcional da organização, capaz de motivar os melhores esforços para a promoção de ações que levassem à mudança. A posição dos funcionários em relação aos movimentos internos de mudança, muitas vezes, foi determinante para o sucesso ou o fracasso destes.

O movimento sindical ao qual os funcionários do Banco do Brasil estão ligados também teve considerável influência em ocasiões específicas, como observaram Pontes (2007) e Rodrigues (2004). Nas situações que se puderam notar, o sindicato, preferencialmente, surgia em contraposição à visão de mudança. A visão deste, ligada também a movimentos políticos, praticamente em todas as ocasiões era contrária à nova visão da empresa.

Desta forma, dentro do contexto interno, não se poderia omitir o papel do Sindicato dos Bancários como agente influenciador do resultado das ações para mudança. Todavia, a posição do sindicato diante da mudança foi, como no estudo de caso da Cadbury (Child e Smith, 1987), a de manter o status quo, ou a de retornar às práticas e visões primárias da instituição (Pontes, 2007; Rodrigues, 2004).

A política governamental, um agente do contexto externo, também refletiu nos valores e nas crenças dos funcionários, alterando, desta forma, o contexto interno. Um dos exemplos pode ser citado nas discussões a respeito da privatização da instituição, nas quais o governo federal era o grande determinador do futuro da organização. Nesta situação, havia uma parcela do corpo de funcionários que rechaçava a ideia da privatização. Entretanto, à época da principal crise financeira da instituição, havia outra parcela de empregados que via na privatização a única salvação para a empresa. 
Outra situação em que o governo federal, como um agente do contexto externo, influenciou diretamente o contexto interno foi em 1996 quando o Banco do Brasil necessitou de aporte de capital para evitar a falência. As consequências internas destas medidas foram inegáveis.

Desta forma, o governo federal se mostrou como uma ponte entre o contexto externo e o interno, levando as mudanças do ambiente diretamente, em casos pontuais como os citados, para dentro da organização. Vale ressaltar que a área que separa o governo federal, como um agente externo do contexto interno do Banco do Brasil, é também acinzentada. Esses fatores confirmam a dificuldade de se estabelecer uma dicotomia na análise dos contextos interno e externo, bem como a necessidade de se proceder a uma análise multinível, tal como destaca Pettigrew (2001).

O cordão umbilical do Banco do Brasil com o governo federal não havia sido ainda completamente cortado com a perda da conta movimento em 1986. Talvez um "corte" maior tenha sido dado 1996 com o aporte de capital de 8 bilhões de reais à época, e cortes seguintes ainda sendo dados com as ofertas públicas de ações e a entrada do conglomerado no Novo Mercado da Bovespa. Salienta-se que, ainda hoje, o governo federal é o acionista majoritário do Banco do Brasil, e nomeia seu presidente e conselho diretor.

Uma situação que não pode ser descartada no contexto interno do Banco do Brasil foi a administração Xavier (pseudônimo) na década de 1990. Todos os entrevistados citaram, em um momento ou outro, a sua administração em específico. É importante observar que tal destaque não foi realizado em nenhum outro caso. Essa ênfase em torno do papel do líder como estimulador da mudança confirma a visão de Burke, Lake e Paine (2009). Ainda de acordo com Pettigrew (1985a), as ações gerenciais são fundamentalmente alocadas na percepção e no entendimento diferenciados do contexto intraorganizacional e socioeconômico, e este contexto não se configura apenas como algo que se pode compreender, mas algo que pode ser mobilizado para criar efeitos práticos (Pettigrew, 1985a).

A posição dos novos funcionários da instituição como atores da mudança no contexto interno também é outra questão a ser considerada. A nova situação em que foram contratados, as novas condições e a agregação do perfil mercadológico puderam ser observadas como fatores que colaboraram fortemente na aquisição dos objetivos da visão da transformação.

Um fenômeno bastante importante começou a desenrolar-se com os movimentos de demissão voluntária ou incentivada. Buscando a adequação do seu orçamento (onde as despesas de pessoal significam considerável parcela), a empresa iniciou alguns processos — alguns mais extensos do que outros - para desligamento de funcionários próximos da aposentadoria ou aptos para tanto, mas que continuavam na ativa. O resultado é que, em algumas situações, como em 2007, o número de funcionários desligados superou o inicialmente desejado, levando a uma renovação significativa do quadro.

Vários entrevistados concordaram que, atualmente, há uma dificuldade de capacitação da força de trabalho gerencial no banco. O perfil do funcionário-médio da instituição mudou significativamente nos últimos anos, e a cultura organizacional tem sido, em alguns pontos, bastante alterada em relação ao que costumava apresentar até a última década do século passado. 
Enquanto os novos funcionários são também o conteúdo de algumas das mudanças, eles também oportunizaram a criação de um novo contexto interno que veio a formar um círculo virtuoso, sob o ponto de vista do sucesso da implantação das mudanças. Desta forma, mais uma vez, pode-se estabelecer a íntima conexão entre contexto, processo e conteúdo da mudança (Pettigrew, 1988).

\subsection{0 processo da mudança}

De acordo com os estudos de Pettigrew (2001; 1996; 1988; 1987; 1985a; 1985b), o processo da mudança pode, muitas vezes, tangenciar o conteúdo da mudança. No presente estudo de caso pode-se afirmar que, ao analisar as mudanças no Banco do Brasil, cada ação indicada poderia ser considerada como conteúdo da mudança. Todavia, de acordo com as conclusões obtidas nesta pesquisa, viu-se que as mudanças menores foram parte do processo para o alcance das mudanças maiores.

Desta forma, pode-se perceber uma série de "conteúdos" de mudanças menores sendo transformados em "processos" que levaram às grandes mudanças estratégicas na organização. Para elucidar a questão pode-se tomar como exemplo a admissão de novos funcionários na instituição. Analisado isoladamente, este fato poderia ser considerado como conteúdo da mudança. Todavia, se analisado dentro de seu contexto amplo, ver-se-á que se trata de um processo pelo qual a organização buscou a aquisição de novas competências e características que a permitissem realizar sua nova visão estratégica.

Assim, espera-se que o entendimento do processo da mudança seja possibilitado por meio da visão generalizante da mudança estratégica no Banco do Brasil. Não se deve, portanto, encarar os eventos descritos como uma série de mudanças desconexas sem um elo lógico unificador e superior (Pettigrew, 2001; 1996; 1988; 1987; 1985a; 1985b).

Neste ponto, pode-se perceber o conceito da mudança teleológica trazido por Van de Ven e Poole (1995), no qual as mudanças organizacionais são um reflexo da condição precípua de as organizações existirem para a aquisição de seus objetivos. Ou seja, as mudanças menores (porém significativas) no Banco do Brasil foram dadas para que os objetivos maiores da instituição fossem atingidos.

Para que as mudanças fossem alavancadas, a instituição iniciou o processo destas em sua própria administração. A visão da presidência e dos altos escalões gerenciais foi mudada pelo cenário que se desenrolava. Como resultado desta nova visão, as mudanças começaram a ocorrer de forma significativa em toda a instituição (Van de Ven, 1992).

Os símbolos que permeavam todo o corpo funcional foram bastante modificados. Alguns foram reforçados, outros substituídos e com outros, ainda, houve uma tentativa de eliminação. Estas foram mudanças consideráveis, pois tais símbolos transpareceram como tendo grande vulto e influência dentro da organização.

O antigo Banco do Brasil estatal, estabelecido em um mercado exclusivo e protegido, praticamente insociável com uma organização competitiva, foi transformado em um conglomerado rentável para todos os seus acionistas, inclusive o próprio governo federal. 
A maior parte dos entrevistados apontou as ações de desligamento de funcionários como bastante impactante na empresa, representando uma grande mudança da organização. Com estes desligamentos, a instituição não estava apenas gerenciando suas finanças, mas transparecia uma manobra no gerenciamento de sua cultura e de seus valores. Por um lado, a mesma perderia considerável e incalculável valor na forma do conhecimento dos funcionários que se desligavam, mas, de outro, abria-se a oportunidade para a incorporação de competências que a empresa dificilmente possuiria de outra forma.

Assim, a instituição passou por um processo de mitigação da sua base funcional, sem realizar concursos, com desligamentos em massa e com a constante saída natural dos funcionários da casa. A entrada dos novos funcionários foi uma parte do processo de mudança que, diferentemente, foi muito bem recebida por todo o corpo funcional e pela administração. Muitos viam neste ato a oportunidade de tornar a empresa definitivamente eficiente e competitiva no futuro. Como observou o analista financeiro da consultoria Austin, "é um desafio uma instituição ser grande, eficiente e pública" (Bueno, 2008).

Pettigrew (1985b) apontou que pode haver uma polarização entre funcionários "veteranos" e "novatos" como forma de tensão política na organização durante o processo. Observou-se, em certa medida, esta tensão entre funcionários antigos e os admitidos após 1998 nos objetivos e nas visões organizacionais. Houve, também, uma preocupação da empresa em propiciar um convívio harmônico entre os grupos, uma vez que as diferenças culturais e situacionais entre um e outro eram consideráveis. De acordo com os dados, o processo de mudança foi bastante marcado pelas ações na área dos recursos humanos, corroborando o estudo de César (2010). Da mesma forma, destacam-se as manifestações a favor e as reações contrárias ao processo de mudança.

A falta de experiência da organização com as novas realidades que se instalavam em seu contexto levou-a a buscar referenciais e modelos de desenvolvimento nas obras de diversos autores, na contratação de consultorias e também em benchmarkings em diversas outras organizações, caracterizando, mais uma vez, um isomorfismo mimético (Dimaggio e Powell, 2005).

Este processo trouxe novas ideias, construtos e práticas e ajudou a solidificar a nova visão organizacional. Como seria de se esperar, nem todas as ações obtiveram o sucesso desejado. Outras táticas adotadas tiveram de ser completamente abandonadas, e outras foram adaptadas, revistas ou acrescentadas para que se adequassem à realidade da instituição.

Os modelos organizacionais foram alterados para que a organização buscasse a eficiência desejada. Em dados momentos, buscou-se a centralização, em outros momentos, a especialização. Em outras situações, ainda, a diversificação dos funcionários foi tida como meta. A polivalência dos gerentes de agência também foi almejada. Finalmente, foi observado que muitas mudanças foram trazidas como parte do processo que deveria conduzir toda a organização à sua reorientação estratégica.

Para que a instituição conseguisse levar a termo as mudanças, o investimento no treinamento e na educação dos seus funcionários foi basal. Houve, por parte da instituição, investimentos elevados em educação corporativa e educação formal. 
Muitas modalidades de educação corporativa foram trazidas aos funcionários. A criação da Universidade Corporativa do Banco do Brasil (Unibb), em 2002, foi o marco que consolidou a intenção da instituição de promover o acesso contínuo dos funcionários ao treinamento e ao desenvolvimento. Esta estratégia, segundo afirmação de um dos entrevistados, foi fundamental para o sucesso da organização no processo de transição para o cenário de alta competitividade do mercado.

Estes investimentos em treinamento se tornaram incrementais, na medida em que a alta administração percebeu os retornos positivos das ações de educação dos funcionários sobre as receitas do conglomerado. Atualmente, dentro da prática corporativa do balanced scorecard, a organização exige um número de horas de treinamento mínimo para cada funcionário.

Em síntese, o processo da mudança no Banco do Brasil foi dinâmico, no sentido de que várias ações foram tomadas para que a organização realmente buscasse a reorientação estratégica. Algumas destas ações não surtiram o efeito desejado e, em algumas outras, o efeito foi um tanto quanto diverso, embora, não contrário aos planos da empresa.

\subsection{0 conteúdo da mudança}

O conteúdo da mudança do Banco do Brasil pode ser sintetizado na mudança de sua missão, visão e cultura. Este seria o tronco do conteúdo da mudança na organização, de onde os ramos das mudanças acessórias estendem seus próprios "porquês".

O Banco do Brasil precisou mudar muito de sua própria razão de existência, a partir da perda da conta movimento. Com este evento, ficou claro que o banco anterior, que chegou a exercer o papel de Banco Central do Brasil, deveria, a partir daquele momento, buscar novos objetivos e novas formas de se manter.

Esta conclusão pode ser mais facilmente compreendida ao se buscar entender os porquês das mudanças no período. Percebe-se que as mudanças como o desenvolvimento da tecnologia, as políticas de recursos humanos e as alterações na estrutura organizacional, dentre outras, apesar de "conteúdo", são também etapas que conduzem a um objetivo maior.

Este objetivo pode ser dado em função da expansão dos negócios, do aumento da lucratividade e da competitividade, mas pode, também, ser resumido na busca da própria sobrevivência da empresa em um cenário cada vez mais dinâmico. Essa questão da mudança como necessária à sobrevivência foi abordada por Pettigrew $(2001 ; 1996 ; 1988 ; 1987 ; 1985 a$; 1985b) e Child e Smith (1987), entre outros.

Em uma esfera menos generalizante, pode-se observar que o conteúdo das mudanças acessórias no Banco do Brasil se estendeu desde o seu parque tecnológico até o seu quadro funcional. Pode-se concluir, de acordo com as observações de Pettigrew (1985a; 1985b;1988; 1996) e Hardy (1996), que a própria cultura organizacional do Banco do Brasil foi alterada.

O Banco do Brasil, firmemente alicerçado em sua origem governamental e burocrática, necessitou, em um curto período de tempo, de vultuosas mudanças em sua administração, portfólio de produtos, corpo funcional e cultura. Pode-se afirmar que toda a estrutura orga- 
nizacional da também empresa foi alterada. Enfim, nos termos trazidos por um dos entrevistados da pesquisa, é pertinente se considerar que nas últimas duas décadas houve vários "Bancos do Brasil".

A atual missão da empresa é "ser a solução em serviços e intermediação financeira, atender às expectativas de clientes e acionistas, fortalecer o compromisso entre os funcionários e a empresa e contribuir para o desenvolvimento do País" (Banco do Brasil, 2009c). Nessa missão, pode-se notar a forte orientação aos resultados financeiros, no sentido de atender às expectativas dos acionistas. Reflete também a nova orientação ao cliente que começou a ser buscada após a perda da conta movimento. De igual forma, o avanço sobre o mercado como "a" solução em serviços de intermediação financeira, em vez de "uma". Também nota-se a expressão dos símbolos da empresa junto aos funcionários, uma das características de destaque nesta pesquisa. E, finalmente, o objetivo social de contribuir para o desenvolvimento do país, implícito em todos os espectros deste desenvolvimento, desde o econômico até o social e o ambiental.

Sinteticamente, o conteúdo da mudança no Banco do Brasil foi a sua própria razão de existir, na forma de sua missão e dos novos papéis que a organização passou a assumir e a desempenhar após a perda da conta movimento. Desta mudança, a organização buscou proteger a excelência e a reputação anteriores, de forma a manter o núcleo da identidade cultural da organização e a sua legitimidade (Dimaggio e Powell, 2005; Crubellate, Grave e Mendes, 2004; Carvalho, Vieira e Lopes, 1999; Gimenez, Hayashi e Grave, 2007).

\section{Considerações finais}

O objetivo geral deste artigo foi o de analisar o processo, o contexto e o conteúdo das mudanças estratégicas ocorridas no Banco do Brasil no período compreendido entre 1996 e 2012. De uma forma ou de outra, o processo da transformação do Banco do Brasil em uma empresa voltada ao mercado, no período pós-perda da conta movimento, foi incremental e pautado por acertos e erros.

Observou-se, no Banco do Brasil, que os contextos externo e interno, com predominância do primeiro, foram grandes determinantes do processo de mudança na organização.

O processo pelo qual as mudanças ocorreram é intrincado e recorre, constantemente, às suas bases nos contextos interno e externo, numa relação recursiva que, por vezes, podese admitir até mesmo a influência em fluxo contrário, haja vista as dimensões das mudanças conduzidas.

A mudança no Banco do Brasil, como se observou, foi dada, afinal, sobre a sua própria missão e posicionamento, criando uma tensão intrínseca em seu cumprimento. Esta tensão decorre de a instituição ter um papel social implícito em sua razão de existir e também do desejo de auferir resultados para seus acionistas. Em uma análise simplista, poderia parecer que as necessidades de geração de lucros e de ação social seriam forças contrárias, em que a energia despendida em uma atividade seria drenada de outra. 
Como observou Hastings (1995), os bancos comerciais federais devem carregar a integração financeira do país, dando especial atenção a determinados focos da política federal, como a agroindústria e a exportação. No caso do Banco do Brasil, foi marcante a preocupação com a manutenção do objetivo social, como destacado neste trabalho, retratado em todo o processo de reorientação estratégica. De acordo com os entrevistados, era importante que o Banco do Brasil se tornasse uma nova instituição, mas que esta mudança não afetasse uma de suas qualidades mais distintivas. Esta qualidade é o papel social e de serventia aos interesses do país.

Cada uma das inúmeras mudanças levantadas na pesquisa ora apresentada poderia gerar muitos estudos sobre suas características, sobretudo nos termos de contexto, processo e conteúdo. A impossibilidade presente de uma prospecção profunda em cada um dos temas é limitadora de um número de informações.

Estudos de caso, como é de comum conhecimento, não podem, obviamente, oferecer generalizações no aspecto estatístico, mas mesmo estudos de caso único podem ser muito úteis à pesquisa sobre a mudança estratégica (Pettigrew, 1985a). As mudanças mais recentes podem se mostrar tão ou mais importantes do que as primeiramente observadas no Banco do Brasil, à época da perda da conta movimento. Isto porque somente com o decorrer do tempo os efeitos destas alterações serão mais amplamente compreendidos. Nesse sentido, vale ressaltar que muitas vezes é mais fácil a análise das mudanças antigas do que a análise das mudanças mais recentes (Pettigrew, 1985a).

Com esta pesquisa, espera-se ter trazido às teorias sobre mudança organizacional, especialmente de empresas públicas, um caso significativo, pois “(...) por meio da empresa Banco do Brasil se pode pensar o próprio Brasil” (Rodrigues, 2004:372). A visão comum do mercado sobre as instituições públicas, como visto, ainda carrega os resultados das organizações burocráticas e ineficientes de tempos passados. Estes são "esqueletos" que acabam por lançar novos desafios às administrações das empresas públicas modernas, que desejam transformar suas instituições em empresas comprometidas com sua função social e, ao mesmo tempo, se mostrar rentáveis e sustentáveis.

\section{Referências}

ALI, Nazim; BALOCH, Qadar B. Job satisfaction and employees turnover intention: case study of NWFP Pakistan based banking sector. Institute of Interdisciplinary Business Research, v. 2, n. 5, p. 39-66, 2010.

ANJANI, P. K.: DHANAPAL, Dr. D. Impact of employee commitment on readiness for change in banking sector in Salem district. Sona Global Management Review, v. 6, n. 3, p. 24-34, 2012.

BANCO DO BRASIL. 200 Anos. Brasília: Associação Nacional dos Funcionários do Banco do Brasil, Mensal, 2008a.

BANCO DO BRASIL. Diretoria de distribuição e canais de varejo. Conhecendo o acordo de trabalho rede varejo. Brasília, $2007 \mathrm{~b}$. 
BANCO DO BRASIL. Educação corporativa. Disponível em: <www44.bb.com.br/appbb/portal/bb/ unv/UniversidadeGrdNumeros.jsp> .Acesso em: 2 mar. 2009a.

BANCO DO BRASIL. Estatuto Social. Disponível em: <www.bb.com.br/portalbb/ page1,136,3510,0,0,1,8.bb? codigoMenu $=824 \&$ codigoNoticia $=672 \&$ codigoRet $=961 \&$ bread $=$ 2>. Acesso em: 9 mar. 2009d.

BANCO DO BRASIL. História do Banco do Brasil. Disponível em: <www.bb.com.br>. Acesso em 23 dez. 2008b.

BANCO DO BRASIL. Informações contábeis: séries históricas. Disponível em: <www.bb.com.br/ portalbb/page22,136,3469,0,0,1,8.bb? codigoNoticia=613\&codigoMenu=428>. Acesso em: 11 mar. 2009b.

BANCO DO BRASIL. Missão. Disponível em: <www.bb.com.br/portalbb/page22,102,2681,0,0,1,6. $\mathrm{bb}$ ? codigoNoticia $=1508 \&$ codigoMenu $=1208>$. Acesso em: 10 mar. 2009c.

BANCO DO BRASIL. Notícias 2012. Disponível em: <www.bb.com.br/portalbb/ page118,3366,3367,1,0,1,0.bb?codigoNoticia=32381>. Acesso em: 3 jan. 2013.

BANCO DO BRASIL. Relatório anual 2010. Disponível em: <www45.bb.com.br/docs/ri/ra2010/ port/index.htm > . Acesso em: $20 \mathrm{dez} .2012$.

BANCO DO BRASIL. Vice-presidência de finanças, mercados de capitais e relações com investidores. Relatório. Análise de Desempenho 2006. Brasília, 2007a.

BAUER, Martin W.; GASKELL, George. Pesquisa qualitativa com texto, imagem e som: um manual prático. Rio de Janeiro: Vozes, 2012.

BUENO, Denise. Um agente público com modos de mercado. Valor Econômico: Especial, São Paulo, p. 4-8, out. 2008.

BURKE, Wyatt W.; LAKE, Dale G.; PAINE, Jill W. Organizational change: a comprehensive reader. San Francisco: Jossey-Bass, 2009.

CARVALHO, Cristina A. P. de; VIEIRA, Marcelo M. F.; LOPES, Fernando D. Contribuições da perspectiva institucional para análise das organizações. In: ENCONTRO ANUAL DA ANPAD, 23., 1999, Foz do Iguaçu. Anais... Foz do Iguaçu: ANPAD, 1999. p. 1-15.

CÉSAR, Ana Maria. A morte simbólica em mudanças organizacionais: o caso do Banco do Brasil. Revista de Administração Contemporânea, v. 14, n. 1, p. 172-188, 2010.

CHILD, John; SMITH, Chris. The context and process of organizational transformation - Cadbury limited in its sector. Journal of Management Studies, Manchester, v. 6, n. 24, p. 565-593, 1987.

CRUBELLATE, João Marcelo; GRAVE, Paulo S.; MENDES, Ariston A. A questão institucional e suas implicações para o pensamento estratégico. Revista de Administração, edição especial, v. 8, p. 3760, 2004.

DIMAGGIO, Paul J.; POWELL, Walter W. A gaiola de ferro revisitada: isomorfismo institucional e racionalidade coletiva nos campos organizacionais. Revista de Administração de Empresas, v. 45, n. 2, p. 74-89, 2005. 
FLICK, Uwe. Uma introdução à pesquisa qualitativa. Porto Alegre: Artmed, 2009.

FRANCO, Afonso A. M.; PACHECO, Cláudio. História do Banco do Brasil. Rio de Janeiro: AGGS, 1979.

GIMENEZ, Fernando A. P.; HAYASHI, Paulo J.; GRAVE, Paulo S. Isomorfismo mimético em estratégia: uma ferramenta para investigação. Revista de Administração Mackenzie, v. 8, n. 4, p. 35-59, 2007.

HARDY, Cynthia. Understanding power: bringing about strategic change. British Journal of Management, special issue, v. 7, p. 3-16, 1996.

HASTINGS, David F. Uma opinião sobre o papel dos bancos estatais no Brasil Real. RAE Light, v. 2, n. 6, p. 9-11, 1995.

LIMA, Daniel. MP 443 serve para aumentar a liquidez do mercado, diz Mantega. Agência Brasil. Disponível em: <www.agenciabrasil.gov.br/noticias/2008/10/22/materia.2008-10-22.7627652504/ view>. Acesso em: 22 out. 2008.

MACHADO-DA-SILVA, Clóvis L.; FONSECA, Valéria S.; FERNANDES, Bruno H. R. Mudança e estratégia nas organizações: perspectivas cognitiva e institucional. In. VIEIRA, Marcelo M. F.; OLIVEIRA, Lucia M. B. Administração contemporânea: perspectivas estratégicas. São Paulo: Atlas, 1999. p. 102-118.

NAVARRO, Pablo; DÍAZ, Capitolina. Análisis de contenido. In: DELGADO, Juan M.; GUTIERREZ, Juan (Org.). Métodos y técnicas cualitativas de investigación en ciencias sociales. Madri: Sintesis, 1994. p. 177-224.

PETTIGREW, Andrew M. A cultura das organizações é administrável? In: FLEURY, Maria Tereza Leme; FISCHER, Rosa Maria (Org.). Cultura e poder nas organizações. São Paulo: Atlas, 1996. p. $145-153$.

PETTIGREW, Andrew M. Context and action in the transformation of the firm. Journal of Management Studies, v. 24, n. 6, p. 649-670, 1987.

PETTIGREW, Andrew M. Contextualist research: a natural way to link theory and practice. In: LAWLER, E. (Ed.). Doing research that is useful in theory and practice. San Francisco: Jossey Bass, 1985a.

PETTIGREW, Andrew M. Examining change in the long-term context of culture and politics. In: PENNINGS, Johannes M. et al. (Ed.). Organizational strategy and change. São Francisco: Jossey Bass, 1985b. p. 269-318.

PETTIGREW, Andrew M.; WOODMAN, Richard W.; CAMERON, Kim S. Studying organizational change and development: challenges for future research. Academy of Management Journal, v. 44, n. 4, p. 697-712, 2001.

PETTIGREW, Andrew M. Understanding change in the NHS. Public Administration, v. 66, n. 3, p. 297-317, 1988.

PONTES, Luiz F. O bancário, o banco e a criatividade: aspectos históricos-culturais para uma sociedade criativa. Tese (doutorado) — Universidade de Brasília, Brasília, 2007. 
RODRIGUES, Lea C. Metáforas do Brasil: demissões voluntárias, crise e rupturas no Banco do Brasil. São Paulo: Annablume, 2004.

SERRA, José. Ciclos e mudanças estruturais na economia brasileira do após-guerra. Revista de economia e política, v. 2/2, n. 6, p. 5-45, 1982.

VAN DE VEN, Andrew; POOLE, Marshall S. Explaining development and change in organizations. The Academy of Management Review, v. 3, n. 20, p. 510-540, 1995.

VAN DE VEN, Andrew. Suggestion for studying strategy process: a research note. Strategic Management Journal, v. 13, n. 1, p. 169-188, 1992.

VASCONCELOS, Flávio C. A institucionalização das estratégias de negócios: o caso das start-ups na internet brasileira em uma perspectiva construtivista. Revista de Administração Contemporânea, v. 8, n. 2, p. 159-179, 2004.

VICENTE-LORENTE, José D.; ZÚÑIGA-VICENTE, José Á. Testing the time-variancy of explanatory factors of strategic change. British Journal of Management, v. 17, p. 93-114, 2006.

YIN, Robert K. Estudo de caso: planejamento e métodos. São Paulo: Bookman, 2007.

Alexsander Dauzeley da Silva é mestre em administração pelo Curso de Mestrado Profissional em Administração da Universidade do Estado de Santa Catarina (Udesc) e assessor do Banco do Brasil. E-mail: dauzeley@gmail.com.

Graziela Dias Alperstedt é professora associada do Departamento de Administração Empresarial e do Programa de Mestrado em Administração da Universidade do Estado de Santa Catarina (Udesc). E-mails: gradial@gmail.com; graziela@udesc.br. 